\title{
The Verb in Arabistic Literature
}

\section{1} The Verbal System in Arabic and Semitic

Unlike the Arab grammarians, whose grammatical description of the Arabiyya was for the most part self-contained, betraying no interest in parallels found in the sister languages, Western scholars in the past two centuries have studied Classical Arabic as an exemplar-albeit prominent—of the overall Semitic bundle of languages. Consequently, their analysis of Arabic data usually involved some comparison, active or latent, to data found in other Semitic languages, as well as some assumptions as to the evolution of the Semitic system in general. As native speakers of modern European languages, also well-versed in the Greco-Latin tradition, Western scholars had a different set of categories and questions in mind than their Arab predecessors. We shall see below how all this shaped their view of the tense system, contributing to its becoming what Goldenberg has described as the 'weakest point in the Semitic verbal grammar.'

For Western scholars, the problem of the tenses in Semitic languages, and specifically in Arabic, has been essentially a problem of translation. As many of them admitted, even a partial correspondence between the tenses in Semitic and in Indo-European languages is hard to identify. ${ }^{2}$ This lack of correspondence resides first of all in the compactness of the Semitic system, which consists of a relatively small number of verbal forms. ${ }^{3}$ However, more acute is the problem of defining the meaning of these forms. As Reckendorf puts it: Wir sollen Verba finita begreifen, die zeitlos sind und zumal unsere Perfekta und Imperfekta zur Übersetzung verwenden, ohne dabei etwas Praeteritales zu denken. ${ }^{4}$ Obviously, the view that the verbal forms in Arabic are 'timeless' is radically different from the one held by the Arab grammarians (see above 2.2), and presents a genuine rethinking of the subject matter. This new view of the verbal system was affected by the Classical and European background of these scholars, as well as by the introduction of the historical-comparative method into Semitic linguistics in the nineteenth century.

1 Goldenberg, Amharic Tense System, 88.

2 E.g. Cohen, Système verbal, 14.

3 E.g. Brockelmann, Grundriss, 2, 144.

4 Reckendorf, Syntaktischen Verhältnisse, 1, $5^{2}$.

(C) MICHAL MARMORSTEIN, 2016 | DOI: 10.1163/9789004310483_004

This is an open access chapter distributed under the terms of the Creative Commons

Attribution-Noncommercial-Non-Derivative 3.o Unported (CC-BY-NC-ND) License 
In his comparative grammar, Brockelmann approaches the problem of the tenses in Semitic languages by going back to its (pre-)historical roots. Following Bauer, he suggests that Proto-Semitic had only one verbal form, the prefixed $y$ aqtul, indifferent of time distinctions. Later on, a second form developed from the nominal clause, namely, the suffixed qatal-, which has come to indicate the 'present' in East-Semitic and the 'perfect' in West-Semitic. ${ }^{5}$ Indeed, this theory may explain the temporal indefiniteness characteristic to $y$-aqtul or the traces of a stative meaning of qatal- in various Semitic languages. However, a more significant point in this reconstruction is the idea that the verbal system in West-Semitic languages is built upon the opposition between two simple forms only: a prefixed one and a suffixed one.

As a matter of fact, the idea that the Semitic verbal system is based on a binary opposition was established long before Brockelmann. In Arabic linguistics, one can go back as far as de Sacy's grammar, who described two simple tenses in Arabic, a 'preterit' and an 'aorist'. ${ }^{6}$ A systematic analysis of the verbal system identifying a binary opposition between the suffixed and the prefixed verbal patterns was first presented by Ewald. In his textbook of Biblical Hebrew from 1870 , Ewald explains the logic underlying his analysis in the following words: '[...] no language, when it introduces distinctions, can start from anything threefold; antithesis is almost always merely simple and thoroughgoing, because elicited by its [counter] thesis [...] Thus, both in thought and language, every distinction is at first drawn between no more than two things. ${ }^{7}$ According to this view — which has become a basic tenet in subsequent literature-an opposition between two forms (or sets of forms) is inherent to the Semitic verbal system. However, the attempts to define this semantic opposition have generated a long dispute among scholars, a dispute which by now 'fills a whole library'. ${ }^{8}$ In the following section, I will shortly review the various opinions as to the ultimate meaning of the verbal forms in Classical Arabic, specifically whether this meaning is regarded as primarily temporal or aspectual.

5 Brockelmann, Grundriss, 2, 145-146.

6 de Sacy, Grammaire arabe, 1, 148.

7 Ewald, Hebrew Syntax, 2. For a detailed discussion of the development of the terms 'perfect' and 'imperfect' in Semitic linguistics, see Goldenberg, Amharic Tense System, 88-94.

8 Sasse, Theory of Aspect, 210. 
In a rather simplified fashion, one could say that the dispute among Western scholars revolves around the question of whether the verbal system is basically tense-oriented or aspect-oriented. Indeed, most scholars do not preclude any of these (and other) semantic notions when listing the various uses of the verbal forms. Rather, it is the identification of the grundbedeutung, the underlying meaning from which all of these uses are derived, which spurs on the controversy.

While the concept of external or relative time was commonly employed by the Arab grammarians (see above 2.2), the concept of the internal time of the verbal situation penetrated Arabic linguistics only in the nineteenth century. ${ }^{9}$ In his Arabic grammar, Ewald was the first to introduce the pair of terms perfectum and imperfectum to account for the semantic distinction marked by the suffixed and the prefixed verbal patterns. ${ }^{10}$ In doing so, Ewald 'set right' the confusing terminology of the Arab grammarians who, according to Brockelmann, 'gave up logical correctness' by naming one pattern after its use (i.e. $m \bar{a} a \underline{d} \bar{\imath}$ 'past') and another after its form (i.e. muḍāric 'resembling'). ${ }^{11}$ Rather than a temporal value, Ewald ascribed to the verbs meanings which would later on be referred to as aspectual. The terms perfect and imperfect became the conventional terms in the Western tradition for the two verbal patterns. It is noteworthy that a further distinction between these two patterns pointed out by Ewald, namely, the modal distinction between certum and incertum, was not maintained in the subsequent literature.

The category of aspect, as was generally defined in regard to Arabic (and Semitic in general), refers to the grammaticalized expression of the distinction between a completed situation and an incomplete situation, signified by the perfect-imperfect pair. Fleischer, for example, argued that a temporal definition of the verbal forms, such as suggested by de Sacy, obscures the 'real essence' of the two verbs, which mark the opposition between 'completion' and 'incompletion.'12 Reckendorf, too, described an opposition between a 'realized' situation and a situation 'in the process of realization' signaled by the Perfekt and Imperfekt. However, unlike Fleischer, Reckendorf does not regard

Although Sībawayhi speaks of a verbal situation which lamyanqați 'has not ceased' (Kitāb 1,1 ), and of a situation which qad waqa'a wa-nqața'a 'has happened and ceased' (Kitāb 1, 73), these occasional comments hardly amount to a systematic theory of aspect.

10 Ewald, Grammatica critica, $112 \mathrm{ff}$.

11 Brockelmann, Grundriss, 2, 145.

12 Fleischer, Kleinere Schriften, 1, $95 \mathrm{ff}$. 
aspect as a pure concept: he recognizes the correlation between completion and anteriority as expressed by the perfect, and (like Ewald before) points out the relation between the aspectual meaning of both forms and their modal and textual functions. The perfect, accordingly, marks 'certainty' and is used to make statements; the imperfect refers to a non-realized situation and is used for descriptions. ${ }^{13}$ Such semantic relations are also identified by other scholars such as Wright, who lists the various temporal uses of the perfect and imperfect, ${ }^{14}$ or Brocklemann, who stresses the contrast between the 'stating' function of the perfect and the 'describing' function of the imperfect. ${ }^{15}$ Nonetheless, it is still the 'opposing aspects inherent in the perfect and the imperfect' which are considered to be fundamental to the verbal system as a whole. ${ }^{16}$

The theory of aspect in Semitic, and particularly in Arabic, was further developed by French scholars. In his monograph on the Semitic verbal system, Marcel Cohen presented a comprehensive analysis of the phenomenon of aspect in Semitic languages and its peculiar traits (compared to Greek or Slavic). ${ }^{17}$ Cohen's theory had great influence on later French Arabists, who endorsed the view that the accompli and the inaccompli in Arabic do not signify a subjective 'situated time', but have an objective aspectual value, such that correlates with certain temporal and modal distinctions. Thus, according to Gaudefroy-Demombynes and Blachère, when not affected by the context, the accompli and the inaccompli have an 'absolute' temporal value: the former is psychologically related to the idea of past, while the latter bears an analogy to the notion of the present or the future. ${ }^{18}$ David Cohen, in his study on the general category of verbal aspect, also identifies a fundamental oppostion of aspect between the two verbal forms in Classical Arabic. However, he defines (after Benveniste) two 'temporalizing' contexts, i.e., narrative and dialogue, in which the accompli and inaccompli acquire a specific temporal value. ${ }^{19}$ Fleisch, too, maintains that the opposition between the accompli and the inaccompli is

\footnotetext{
13 Reckendorf, Syntaktischen Verhältnisse, 1, $53 \mathrm{ff}$.

14 Wright, Grammar, 2, $1 \mathrm{ff}$.

15 Brockelmann, Arabische Grammatik, 118. Elsewhere, the functional distinction between 'stating' (konstatieren) and 'describing' (schildern) is regarded as a grammatical distinction between a 'constative' and a 'cursive' aspect, cf. Brockelmann, "Tempora", $139 \mathrm{ff}$. The latter terms were borrowed by Rundgren, in his studies of the Semitic aspect, and later on by Reuschel, in his study of tense and aspect in the Qurān (see Aspekt und Tempus, 24).

16 Fischer, Classical Arabic Grammar, 102.

17 Cohen, Système verbal.

18 Gaudefroy-Demombynes and Blachère, Grammaire de l'arabe, 246.

19 Cohen, L'aspect verbal, 84-85.
} 
in principle aspectual. However, he admits (like Reckendorf before) that while the accompli can indicate time in itself, when serving as the narrative tense, the inaccompli is never capable of indicating time in itself. ${ }^{20}$

The conclusion that the perfect, as opposed to the imperfect, embodies a temporal component, was arrived at in the Arabistic literature several times. Beeston, for instance, argues that the semantic opposition between the two verbal patterns lies in the value of their 'predicate element', which may be either dynamic or static. This opposition - though not strictly grammatical, but also lexical—is also defined by him as 'aspectual.'. ${ }^{21}$ According to Beeston, 'the only definitely time-marked verb [...] is the suffix set verb in cases where it has dynamic aspect, being then explicitly past'.22 Keeping with the same general idea, Götz, too, contends that a form like kataba, signaling 'retrospective', is marked for time-perspective, whereas a form like yaktubu has no temporal value, its 'relevance' lies solely in its lexeme. ${ }^{23}$

Although the theory of aspect became prevalent in the majority of grammatical descriptions, the tense-oriented approach was not discarded by all. Some one hundred and fifty years after de Sacy, it was Aartun who advocated anew the analysis of qatal-and yaqtul- as plain tense forms, the first marking 'preterit' the second marking 'non-preterit', 'present'. ${ }^{24} \mathrm{~A}$ more sophisticated analysis of the system, following the so-called 'noetic' model, was proposed by Denz. In this model, the verbal forms fit into a grid whose main coordinates are temporal; aspectual distinctions do not exist by themselves, but are logically entailed by the temporal ones. ${ }^{25} \mathrm{~A}$ similar analysis was advanced by Kuryłowicz, who determined a hierarchy of functions of the binary pair qatala-yaqtulu. The primary function of the first, which is the positive member in the opposition, is to indicate anteriority, while the primary function of the latter, which is the neuter-negative member, is to indicate non-anterior or simultaneous action. ${ }^{26}$ In a more recent study, Bahloul, too, employs the tool of markedness to account for the semantic opposition indicated by the perfect and imperfect. According to his analysis, the perfect embodies the positive features of '+anteriority' and

\footnotetext{
$20 \quad$ Fleisch, Verbe arabe, 177.

21 Beeston, Arabic Language, 76.

22 Ibid., 79.

23 Götz, Tempora, 96.

24 Aartun, Altarabischer Tempora.

25 Denz, Verbalsyntax, presents the noetic model in the introduction to his description of the dialect of Kwayriš. A short theoretical outline of this model is also presented in Denz, Tempus und Aspekt?.

26 Kuryłowicz, Studies in Semitic, 8 off.
} 
'+dimensionalization', whereas the imperfect embodies either the negative (-) or the neuter $( \pm)$ values of these features. ${ }^{27}$

The question as to the basic meaning of the suffixed and prefixed patterns in Classical Arabic continues to intrigue modern scholars. Most of them agree that both patterns indicate temporal and non-temporal meanings, however, the exact definition of these is yet a matter of dispute. ${ }^{28}$ It is noteworthy that Comrie's paragraph-long description of the tenses in Classical Arabic has gained currency is recent years, even among Arabists. Comrie cuts to the point by stating that, in addition to their aspectual values, the perfect and the imperfect also embody a component of relative time reference. ${ }^{29}$ Appealing as it is, such a compact analysis can hardly capture the complexity of the system. In fact, one may rightly doubt whether an abstraction at such level reflects at all a linguistic reality, thus whether it brings us any closer to understand the mechanism found in practice in Classical Arabic.

\subsection{Summary}

In this chapter, I have reviewed the ongoing dispute over the semantic opposition marked by the two basic verbal forms fa'ala and yaf'alu in the Arabistic literature. While the binary structure of the verbal system has been commonly accepted (and, in fact, regarded as self-evident), the scholars have been divided as to the basic semantic opposition marked by fa'ala and yaf'alu. We have seen that most scholars, while aiming at compact and clear-cut definitions, come to admit the differences between fa'ala and yaf'alu with respect to their having a temporal value. When applied to these forms, the terms 'perfect' and 'imperfect' turn thus to be misleading in more than one sense: not only do they stand for different meanings than those generally associated with them (considering

27 Bahloul, Arabic Verb, $140 \mathrm{ff}$.

28 Bubenik, Hewson, and Omari, Tense, Aspect and Aktionsart, outline a general model for the tense system of Arabic or better, the Arabic 'type' (Arabic, in this article, stands for all forms of the written and spoken language). The authors contend that 'the familiar morphological opposition katab-a versus $y a-k t u b$ - $u$ is best described by double temporo-aspectual labels past/Performative versus non-past/Imperfective' (45). Although the authors introduce some innovations, specifically the analysis of fa'ala as Performative rather than Perfective (the first fits into the cognitive scheme of 'ascending time', the latter into the scheme of 'descending time'), their study follows by and large the same basic conception of the verbal system as binary and non-symmetrical.

29 Comrie, Tense, 63. 
either the Slavic perfective and imperfective, or the perfect and imperfect in Romance languages), but also, they do not indicate a single functional opposition. While fa'ala is generally described as the complete-anterior form, most scholars have difficulty to capture the content of yaf'alu in positive terms, thus coming full circle to the 'illogical' asymmetry suggested by the Arab grammarians in the first place.

The ongoing controversy over the basic meaning of fa'ala and yaf'alu leads one to think that, while there are certain obvious tendencies, there is no one, basic, category that could crack the logic of the Arabic verbal system. The pursuit of a neat formal definition which will fit all the cases is bound to fail. At the synchronic level, the uses of both forms are too many and diverse; also from a historical perspective, it is hard (if not impossible) to trace the development of the verbs from a primitive state of simple oppositions. Rather, we can only approach a functional definition of the verbal forms by giving due consideration to the particular, concrete, contexts in which they are used. The following chapters are dedicated to a discussion of the structure of context and a close examination of the functions of the verbal forms in different contexts. 